\title{
The Important of Knowledge Management as a Panacea for Sustainable Development
}

\author{
OYEWUMI Fausat Ayobami ${ }^{1}$, OYEDOKUN Tunde Toyese ${ }^{2 *}$ and 0 TONEKWU Florence Onyeisi ${ }^{1}$ \\ ${ }^{1}$ University of Ilorin Library, Nigeria \\ ${ }^{2}$ Department of Library and Information Science, University of Ilorin, Nigeria
}

Submission: February 13, 2019; Published: June 25, 2019

"Corresponding author: Tunde Toyese Oyedokun, Mater Graduate of Department of Library and Information Science, Faculty of Communication and Information Sciences, University of Ilorin, Ilorin, Nigeria

\begin{abstract}
Sustainable Development Goals is a global partnership that tends to set the world on the path of inclusive and sustainable development. The seventeen goals, one hundred and sixty-nine targets, as well as three hundred and four indicators, are set to achieve three broad objectives that include a global scale economic development, environmental sustainability and social inclusion. Transforming our world on the path of sustainable development constitute the hallmark of United Nation Assembly's Open Group that set the vision to be accomplished by the year 2030. Agenda 2030 is universally applicable to all nations of the world, which implies that no nation can localize and implement Sustainable Development Goals successfully while working in isolation.

The implication is that the global agenda would be defeated. Going by what is obtainable in the literature, submission of the $17^{\text {th }}$ goal of Sustainable Development Goals that advocate for a global partnership as well as knowledge management initiatives already embarked upon by various stakeholders buttressed the importance of knowledge management imitative for sustainable development. Relevant instances of knowledge management initiatives for the accomplishment of Sustainable Development Goals include United Health Coverage, United Nation Entity for Gender Equality and Empowerment of Women, Knowledge for Development Partnership, and many more. However, setting the world on the path of transformation and global sustainability demand global partnership that strengthen collaboration and sharing of knowledge. It also requires bridging the digital divide between developed and developing countries through the provision of adequate information infrastructure that would incite knowledge sharing and collaboration.
\end{abstract}

Keywords: Knowledge; Knowledge management; Sustainable development goals; Millennium development goals; United nation

\section{Introduction}

Sustainability is the art (that require certain skills) and social science (that following a scientific approach) of upholding, supporting, and maintaining a system or process to remain productive indefinitely. Sustainable development, on the other hand, is the process of meeting development goals through an organizing principle or strategic sustainable plans that ensures indefinite availability of resources for present and future needs [1]. It is a process that fosters a sustainable environment for societal development without compromising the future need for available resources. In consonance to the, Ulrich [2] stressed that sustainable development is concerned with carrying capacity of the natural system with the social, political, and economic challenges faced by humanity with emphases on the present generation's responsibility to regenerate, maintain, and improve planetary resources for use by the future generation.

Sustainable Development Goals [3] was conceived and presented by the United Nation General Assembly's Open Working Group on 19th July 2014 containing 17 goals, accompanying by 169 targets and about 304 indicators, which was subjected to some review before it final endorsement in September 2015 by the head of states and government. United Nations General Assembly Resolution A/RES/70/1 of 25 September 2015 contained the goals, targets and indicators. SDGs covers issues that bothered on poverty, health, education, global warming, gender equality, environmental sanitation, energy, urbanization, social justice and many more running to 304 indicators that measure compliance.

One hundred and ninety-three (193) head of states agreed to set the world on a path to transform the world towards sustainable development by setting out sustainable development agenda for 2030 [3]. SDGs build on the accomplishment of Millennium Development Goals (MDGs) by extending the eight (8) goals of MDGs. While SDGs is on the sustainability of natural resources that take into action interconnectedness of all developmental problems in our society, MDGs is all about development. The three (3) main dimensions of the 17 goals are to record at global scale economic growth, environmental suitability and social inclusion. SDGs bulwark on MDGs (meant for developing countries) and apply universally as a new paradigm for sustainable development 
for all countries. The new agenda (sometimes refers to as the 2030 agenda) was broadened to accommodate other areas such as security, governance, social, economic and environmental aspect of development.

Agenda [4] constitute a cohesive and integrated package of global aspirations. It builds on the achievement of MDGs and addresses the most pressing global challenges of our time, calling upon collaborative partnership across and between countries to balance development in term of economic growth environmental sustainability and social inclusion. Implementation of SDGs started with localization of SDGs by participating nations, institutions, local players and other stakeholders. SDGs are universal goals in which each country will be responsible for developing and implementing national strategies to achieve them and will be expected to track and report progress. The Sustainable Development Goals aim to eradicate poverty and inequalities and spur economic growth while respecting planetary boundaries. The agenda is transformative: they address both gaps in coverage of the MDGs and the underlying problems. There are specific global goals that aim at putting in place policies, institutions and systems necessary to generate sustained investment and growth. There could be no better moment than now for the United Nations to launch the SDGs as a roadmap for the accomplishment of sustainable development by the year 2030 .

Leveraging knowledge for sustainable development constitute the hallmark of knowledge management initiative, as learned citizens embark on long-life learning that equipped them with skills necessary for identification of knowledge gap in their knowledge domain as well as knowing the sources of information at their disposal in solving phenomenon (uncertainty/knowledge gap). Any nation wishing to attain sustainable development ought to work toward attaining the status of a knowledge society where citizens are rightly informed. Attaining this status is highly pivotal, as most successful individuals, group, and organization and by extension nations of the world, are those that best leverage their knowledge base (documented knowledge/information, individual experience, skills, intuition etc.) for sustainable development. In today's social, economic, industrial, political and technological world, knowledge management is an indispensable and essential ingredient in achieving meaningful development. In advocacy to foregoing, Brander [5] posited that in every parts and facet of our society, knowledge is the heart of all resources or factors needed for development. Buttressing the aforestated was Kurz [6] who also affirmed that knowledge is a vital and indispensable resource for sustainable development.

In knowledge economy of today, more value is accord to knowledge as a key driver and social engineering for sustainable development $[7,8]$. In congruence to foregoing, Dumittriu [9] asserted that knowledge is preeminent in all mandates and actions that fuel the dynamics of our globalized and interdependent world that goes beyond thematic or geographical borders. This is so true such that if we are to attain the United Nations' Agenda 2030 , the world must recognize the substantial need of embracing the culture of knowledge sharing across boundaries without barriers. The MDGs is a collection of separate objectives, while that of 2030 Agenda was global and indivisible, which tends to be far remote from disintegration, duplication as well as working in reclusiveness Carbonez [10].

This is where adoption of knowledge management practice for sustainable development became paramount and widespread among various stakeholders advocating for Agenda 2030. Knowledge management constitutes the roadmap for the accomplishment of SDGs because of its concern with extracting value from knowledge repositories and sharing such knowledge with various stakeholders. No stakeholder of agenda [4] can achieve SDGs in isolation without collaboration and sharing of knowledge learned with others. This practice of knowledge sharing will eliminate duplication of effort and waste of scarce resources among participating counties. In today online world with the wealth of information presented therein, Bokova [11] reported that two-thirds of residence of third world countries remain offline. This call for bridging all form of the digital divide that would foster global inclusive development-oriented information society where everyone creates, access, share and leverage knowledge.

Kerkhoff (2014) associated sustainable development as a knowledge-intensive process that was plagued by an inability to connect what we know with sustainable practices. Therefore, adopting knowledge management as elixir vitae for sustainable development advocate for a global practice that foster synergies, cross-fertilization, bottom-up and top-down knowledge transfer, vertical and horizontal learning and knowledge sharing Bury [12]. In recognition of the importance of knowledge management for the accomplishment of global sustainable development. The United Nations, international organizations, and associations such as Universal Health Coverage (creation of World Health Organization), United Nations Entity for Gender Equality and the Empowerment of Women and Knowledge for Development Partnership embarked on knowledge management initiatives that foster collaboration as well as knowledge sharing across the globe [13-15]. Considering this, this paper reviews various knowledge management initiatives documents that bothered on the accomplishment of Agenda [4]

\section{Transforming Our World}

The 2030 Agenda for Sustainable Development Sustainable Development Goals (SDGs) sometimes refers to, as global goals for sustainable development are sets of seventeen (17) goals, one hundred and sixty-nine (169) targets and three hundred and four indicators that measure compliance and localization of implementation process. The initiative was a result of resolution made by one hundred and ninety-three 193-member states and global civil society that participated in United Nation General Assembly of 25 September 2015. To set the world on the path of development that is sustainable, the 17 goals, 169 targets and specific objectives for each goal was enshrined in the United 
Nation's document paragraph 54, A/RES/70/1. Achieving the specific objectives denote accomplishing the 17 goals.

The seventeen goals of SDGs, as well as their specific objectives, are stated thus:

a) Goal One: to end poverty in all its forms everywhere - No Poverty.

b) Goal Two: to achieved food security and improved nutrition through sustainable agriculture - Zero Hunger.

c) Goal Three: to ensure healthy lives and promote wellbeing for all - Good Health for the People.

d) Goal Four: to ensure inclusive and equitable quality education as well as the promotion of lifelong opportunities for all - Quality Education.

e) Goal Five: to achieve gender equality and empowerment for women - Gender Equality.

f) Goal Six: Clean Water and Sanitation.

g) Goal Seven: to ensure access to affordable, reliable, sustainable and modern energy for all - Affordable and Clean Energy.

h) Goal Eight: to promote sustained, inclusive and sustainable economic growth, full and productive employment and decent work for all - Decent Work and Economic Growth

i) Goal Nine: to build resilient infrastructure, promote inclusive and sustainable industrialization, and foster innovation - Industry, Innovation and Infrastructure.

j) Goal Ten: to reduce income inequality within and among counties - Reducing Inequalities.

k) Goal Eleven: to make cities and human settlements inclusive, resilient, and sustainable - Sustainable Cities and Communities.

l) Goal Twelve: to ensure sustainable consumption and production patterns - Responsible Consumption and Production.

m) Goal Thirteen: to take urgent action to combat climate change and its impact by regulating emissions and promoting developments in renewable energy - Climate Action.

n) Goal Fourteen: to conserve and sustainably use the oceans, seas, and marine resources for sustainable development - Life below Water.

o) Goal Fifteen: to protect, restore and promote sustainable use of terrestrial ecosystems, sustainably manage forest, combat desertification, and halt and reverse land degradation and halt biodiversity loss.

p) Goal Sixteen: to promote peaceful and inclusive societies for sustainable development, provide access to justice for all and build effective, accountable and inclusive institutions at all levels - peace, Justice and Strong Institutions.

q) Goal Seventeen: to strengthen the means of implementation and revitalize the global partnership for sustainable development - Partnerships for Goals.

Important of Knowledge Management as a Panacea for Sustainable Development

Human activities have caused our world environment to deteriorate to the extent that it is very difficult for planet earth to be resources self-renewal to meet future resources need of humankind [16,17]. There exists a global sustainability crisis as the world population is increasing (which require more resources for sustainability) at the expense of degrading in environmental natural resources, which is detrimental to our society. Robert et al. [18] give the condition that if society did not desist from polluting the atmosphere and as well, change from unsustainable practices, there would be a decline in environmental potentials and degrade on natural resources to sustain present generation and subsequently future generation needs.

Going by the notion that sustainable development denotes the ability to meet present need of the populace without compromising that of coming generation; then it is very essential for societies to not only find a solution to present predicament but also proactively treat the future emerging ones. No nation can boast to be selfsufficient as our world is interdependent of one another, which necessitate the need for United Nations to imbibe in knowledge sharing and knowledge collaboration, which is the hallmark of knowledge management. The practice of knowledge management becomes the last resort through which the sustainability threat confronting our planet could be jointly tackled.

Just in advocacy to above, Halpern [19] forecasted that in near future our societies would be learnt that developmental sustainability threat is a global phenomenon that requires localization of knowledge garnered from global collaboration. More so, the local communities would be considered as knowledge holders because knowledge reflects on the knowledge that was accumulated by generations of settlers and migrant within a territory. Buttressing important of knowledge was Brander [5] who posited that knowledge is at the nerve center of development, which is very essential for all society that was positioned for sustainable development.

Boom [20] did not miss words when he emphatically asserts that knowledge is a key driver of change that metamorphic into the process of innovation, invention and diffusion that lead to the transformation of ideas that have utility value to societal needs. In consonance to foregoing, Bokova [11] stated that knowledge management initiative is at the heart of the United Nations' Agenda 2030 that lay the foundation for inclusive knowledge societies. Bieckmann [21] posited that knowledge can be tacit (knowledge gain through experience, intuition or belief) or explicit 


\section{Annals of Social Sciences \& Management studies}

(documented knowledge) that recognition of its plurality nature would make knowledge to be properly utilized for legitimizing inclusive development policies.

In pursuit of sustainable development by United Nations and other various stakeholders, it is necessary that knowledge generated by individual stakeholders and nations are captured, inventoried and shared with other stakeholders because sustainable development could not be achieved by individual stakeholder's effort but rather through collaboration effort. In congruence to aforestated was Amouzou [22] who demonstrated that knowledge development is fundamental for sustainable development such that if knowledge garnered through collaboration efforts were utilized effectively in various nations of the world, better health, education, infrastructural development and social wellbeing would be guaranteed.

\section{Agenda Knowledge for Development}

Knowledge for Development Partnership created the global Agenda Knowledge for Development as one of the resolutions made in their meeting in Vienna in October 2016 and that of Geneva in April 2017. The Agenda Knowledge for Development is an initiative that is open to all that wishes to place knowledge and knowledge management at the core center of achieving sustainable development goals. Their mission was to create a global partnership for the development of a peaceful, wealthy, inclusive and sustainable world for all people irrespective of their geographical locations. Stated in apposition, this agenda would help better understand the needs for inclusive knowledge societies as well as manage knowledge responsibly on all level of our societies for the benefits of a peaceful, wealthy and sustainable future.

Knowledge partnership was created to foster collaboration and sharing of knowledge across the globe. The aim of the partnership was to nurture a universal knowledge framework that seeks to provide a guiding principle for dialogue on knowledge, strengthening global knowledge ecosystems as well as contributing to better success in achieving sustainable development goals. The Agenda Knowledge for Development strives for advancing knowledge societies that contribute to the accomplishment of SDGs in various spheres, societies or nations. This they embark upon to create global knowledge partnership Knowledge Development Partnership [4].

\section{Universal Health Coverage (UHC2030) - International} Health Partnership Health System

Universal Health Coverage (UHC) is an offspring of the World Health Organization (WHO) constitution of 1948 that declared sound health as one of the fundament human rights. The rationale for the creation of UHC was to afford people (most especially people from poorest countries) the use of preventive, curative, rehabilitative and palliative health services without exposing them to any form of financial hardship. Most especially, the agenda of UHC was to work toward achieving health-related sustainable development goals of 2030. In recognition of the importance of knowledge management, UHC constitutes a Knowledge Management Working Group (KMWG), a multi-stakeholder platform to strengthen collaboration and contribute to the movement for resilient, sustainable and equitable health systems to attain global health security by 2030 .

The Knowledge Management Working Group (KMWG) met in April 2017 to map out strategies on how networks, alliances and initiatives engaged in knowledge management related to Universal Health Coverage (UHC) and Health System Strengthening (HSS). What constitutes a key advantage for this collaboration is knowledge management that helps to position UHC 2030 to broker knowledge across the HSS and UHC Agenda. UCH 2030 knowledge management landscape analysis report indicated that there is an avalanche of knowledge that is available, but the knowledge remains unknown and less utilized. Knowledge management initiatives such as UHC 2030 are aggregator and disseminator of knowledge that accelerates progress towards developmental goals by pooling resources.

\section{United Nations Entity for Gender Equality and the Empowerment of Women}

United Nations General Assembly established the Entity for Gender Equality and the Empowerment of Women. The vision was to foster gender equality, which grounded on the notion that the involvement of women in SDGs would have a multiplier effect. In the process of fulfilling its mandate to achieve gender equality, it provides support service to the government of participating nations to domesticate, localize, and implement the SDG goal five (Gender Equality).

The organization adopted a knowledge management strategy to collect, disseminate and preserve the intellectual output of participating countries through diverse mechanisms to support the localization of SDG objective of gender equality and women empowerment. The organization objective of adopting knowledge management practice was to ensure knowledge and innovation are documented, analyzed and widely disseminated for uptake and replication. What constitutes the key element of the knowledge management strategy employed include knowledge capturing, analysis and documentation of knowledge captured, knowledge sharing/knowledge transfer as well as knowledge sustainability. Concisely stated, the strategy aims at promoting the sharing of best practices and lesson learned for the implementation of Gender Equality (Sustainable Development Goal 5).

\section{Discussion of Findings}

The SDGs set out objectives across social, economic and environmental sustainability. The goals provide a framework for shared action for people, planet and prosperity. The goals are designed to be implemented by all countries acting in a collaborative partnership. These global objectives are universally applicable, considering different national realities, capacities and levels of development. The realization of global sustainable 


\section{Annals of Social Sciences \& Management studies}

development at its core essentially would require combine and collaborative effort of all stakeholders, which is the hallmark of knowledge management initiatives that tend to achieved set objectives through the process of extracting knowledge from intellectual repository (local communities held knowledge, individual experiences, recorded knowledge, knowledge databases etc.) and sharing such knowledge among various stakeholders.

Various stakeholders at local, national and international level have embarked upon knowledge management initiatives for the accomplishment of SDGs vision 2030. However, the major challenges of knowledge management practice among United Nations are different in the digital environment in which knowledge is developed and utilized, reluctant on the part of participating countries to share knowledge learned as well as the digital divide between developed countries and developing countries. The first world countries are in the forefront of development in term of Information Technology (IT) that serve as drivers and enhancer of knowledge management, while that of third world countries is still at elementary stage.

\section{Conclusion and Recommendation}

Sustainable Development Goal 17 (Partnerships for the Goal) that recaps the whole agenda into implementation and revitalization through global partnership explained in coincidence the importance of knowledge sharing and collaboration, which constitute the core principle of knowledge management. Therefore, knowledge management was authenticated as elixir vitae for implementation of sustainable development at all level of partnership.

In the process of localizing SDGs in various nations, it is very crucial that lesson learned (knowledge garnered in implantation process) are captured, inventoried and shared with all stakeholders if truly the world is ready for sustainable development. More so, the gap between the two sides of the digital divide (developed and developing countries) needed to be bridged through the provision of adequate information infrastructures that enhance collaboration and sharing of knowledge among all nations of the world.

In realization of sustainable development in various societies, knowledge is at the center, therefore access to knowledge base/ intellectual repositories be made free for all, as all habitats of the world constitute major players in Implementation of SDGs.

In knowledge society today, knowledge development is indispensable for sustainable development that transforms into better education, social wellbeing, environmental infrastructure and human capital development. Securing this status of knowledge society require effective utilization of existing and newly generated knowledge for the formulation of developmental policies and implementation.

\section{References}

1. Lynn RK, Eda G (2014) Communicating sustainability for the green economy. ME Sharpe. New York.

2. Ulrich G (2007) Deep roots: A conceptual history of sustainable development. Nachhaltigkeit, Wissenschaftszentrum Berlin für Sozialforschung.

3. Pisano U, Lange LK, Hametner M, Berger G (2015) The Sustainable Development Goals (SDGs) and their impact on the European SD governance framework: Preparing for the post-2015 agenda. European Sustainable Development Network. Austria.

4. Knowledge Development Partnership (2017) Agenda knowledge for development: Strengthening agenda 2030 and the Sustainable Development Goals. Knowledge Development Partnership. Austria.

5. Brander A (2017) Report of the knowledge for development: Global partnership Conference 2017.

6. Kurz S (2017) Preface contribution for agenda knowledge for development: Strengthening agenda 2030 and the Sustainable Development Goals. Knowledge Development Partnership. Austria.

7. Oyedokun TT, Laaro MD, Oyewumi FA, Akanbi ML (2018) Assessment of knowledge management competencies of library and information science professionals in. Library Philosophy and Practice (e-journal). Paper 1919. Nigeria.

8. Nazim M, Mukherjee B (2016) Knowledge management in libraries: Concepts, tools and approaches. Chandos Publishing, Elsevier. UK.

9. Dumittriu P (2016) Knowledge management in the United Nations system. Geneva.

10. Carbonez F (2017) Statement on knowledge for development. Austria.

11. Bokova I (2017) Statement on knowledge for development. Austria.

12. Bury P (2017) Statement on knowledge for development. Austria.

13. Universal Health Coverage (2017) Knowledge management strategy: Draft as of 22 November 2017. Tokyo, UHC2030 Steering Committee. Japan.

14. World Health Organization (2019) What is health financing for universal coverage? Austria.

15. UN Women (2019) Accelerating the progress towards the localization of Sustainable Development Goals. Nairobi, Regional Knowledge Management and Research. Kenya.

16. Rita A, Juuso L, Alina M (2016) The role of knowledge management in strategic sustainable development: Comparing theory and practice in companies applying the FSSD. Master thesis submitted to School of Engineering Blekinge Institute of Technology, Karlskrona, Sweden.

17. Steffen W, Persson A, Deutsch L, Zalasiewicz J, Williams M, et al. (2011) The Anthropocene: From global change to planetary stewardship. Ambio 40(7): 739-761.

18. Robert K, Broman GI, Basile G (2013) Analyzing the concept of planetary boundaries from a strategic sustainability perspective: How does humanity avoid tipping the planet? Ecology and Society 18(2): 5.

19. Halpern A (2017) Statement on knowledge for development. Austria.

20. Boom D (2017) Statement on knowledge for development. Austria.

21. Bieckmann F (2017) Statement on knowledge for development. Austria.

22. Amouzou B (2017) Statement on knowledge for development. Austria. 
This work is licensed under Creative Commons Attribution 4.0 License

DOI: 10.19080/ASM.2019.03.555619

\section{Your next submission with Juniper Publishers} will reach you the below assets

- Quality Editorial service

- Swift Peer Review

- Reprints availability

- E-prints Service

- Manuscript Podcast for convenient understanding

- Global attainment for your research

- Manuscript accessibility in different formats

( Pdf, E-pub, Full Text, Audio)

- Unceasing customer service

Track the below URL for one-step submission https://juniperpublishers.com/online-submission.php 